\title{
Degenerative Disease In Lumbar Spine Of Military Parachuting Instructors
}

\author{
Y Bar-Dayan, M Weisbort, Y Bar-Dayan, GJ Velan, M Ravid, D Hendel, \\ J Shemer
}

Yosefa Bar-Dayan MD, MHA $^{(1,2)}$

Email:

bardayan@netvision.net.il

Moshe Weisbort $\mathrm{MD}^{(3)}$

Yaron Bar-Dayan MD, MHA (2)

Gad J Velan MD ${ }^{(3)}$

Mordchai Ravid MD FACP ${ }^{(1)}$

David Hendel MD ${ }^{(3)}$

Joshua Shemer MD ${ }^{(2)}$

(1) Department of Medicine,

Meir Hospital, Kfar-Sava, and the Sackler Faculty of Medicine, Tel-Aviv University, Tel Aviv, Israel.

(2) Israel Defense ForceMedical Corps.

(3) Department of Orthopedic surgery, Campus Golda, Rabin Medical Center, PetachTikva, and Sackler Faculty of Medicine, Tel-Aviv University,

Tel Aviv, Israel.

\section{ABSTRACT}

Parachuting, be it static line or skydiving, places enormous stresses on the human spine. It is, therefore, important to determine the prevalence and severity of degenerative changes in the lumbar spine of subjects who practice this sport activity.

Seventy four parachuting instructors, mean age 33 years and with an average of 410 static line and skydiving jumps, were included in the study. Past radiographs were examined and compared to current anterolateral and lateral views of the lumbar spine, in order to determine the prevalence of degenerative changes and document possible progression.

Doubtful radiographic changes in the lumbar spine were identified in 47.4 percent of the parachuting instructors, mild degeneration in 9.6 percent, moderate degenerative disease in 10.9 percent and severe radiographic changes in 5.5 percent. Schmorll nodes were found in 8.1 percent of the subjects. Traction spurs - osteophytes were identified in 6.8 percent. The degenerative changes correlated with age and the number of jumps. Spondylolysis of L5-S1 and L3L4 segments were observed in $\mathbf{1 2 . 2}$ and 1.4 percent respectively. Progressive spondylolisthesis was found in 2 subjects.

No correlation was found between the severity of radiographic changes and either the prevalence and the severity of low back pain

The present findings provide a rational for considering repeated sheer stress as an etiology of degenerative changes in the spinal cord, and as a possible contributing factor to the pathogenesis of spondylolysis.

Further study has to be done comparing parachuting instructors to a nonparachuting group, or equivalent physically active individuals, in order to assess the effect of sport-background on the development of degenerative changes.

Key words: Spine, Parachuting, Degenerative disease.

\section{Introduction}

The spinal column is second only to the lower limbs in injuries caused by parachuting (1-3). Most reports in the literature contain data regarding acute trauma to the spine and spinal cord as a result of a single parachuting injury (4-7).

Permanent changes in the cervical and thoracic spine caused by repeated trauma in military parachutists were previously reported. No differences were found, however, in the frequency of permanent changes in the lumbar spine between the study and matched control groups (8). The present study was undertaken in order to examine the prevalence of permanent radiographic changes in the lumbar spine of military parachuting instructors, thereby assessing the importance of repeated mechanical stress in the development of such pathology.

\section{Methods}

\section{Subjects}

Seventy four parachuting instructors at a training centre involved in static line jumps and skydiving gave informed consent to participate in this study. All were males, mean age 33 (range 22-54) and had performed an average of 410 jumps. The majority were performed with ordinary military parachutes, which are opened by a static line and are not steerable. Some were with sport parachutes, which were steerable and were opened, after a free fall, by ripcord. The majority of the jumps were made without equipment on a sandy soil at the training ground.

All the instructors were interviewed by one of us (YBD), and questioned for complaints of low back pain, its severity and frequency. All had past and current anteroposterior, lateral and oblique radiographs of the lumbar spine. Adequate genital shielding was maintained during this procedure.

\section{Evaluation of radiographs}

Radiographs were studied in a blind fashion by two senior orthopedic surgeons (DH \& MW). In accordance with the criteria set by Frymoyer et al (9), lateral radiographs of the lumbar spine were assessed to the presence of: (i) Schmorll nodes (ii) lumbar lordosis as manifested by the Cobb angle measured between first and fifth lumbar vertebra (iii) Traction spurs (iv) disc space narrowing (11) and (v) wedging of intervertebral discs. Anteroposterior radiographs were assessed for: (i) 
transitional vertebra (ii) transverse process length and (iii) occult neural arch defects. Each radiograph was given a grade according to the severity of these findings. Narrowing and osteophytosis were assessed separately using 5 points grading scale $(0=$ normal, $1=$ doubtful, $2=$ mild, $3=$ moderate, $4=$ severe) and the highest grade for either feature was taken (38) (Table 1).

Table 1. Severity scale of permanent radiographic changes in the lumbar spine.

\begin{tabular}{|l|l|}
\hline Severity & Grade \\
\hline Normal & 0 \\
\hline Doubtful & 1 \\
\hline Mild & 2 \\
\hline Moderate & 3 \\
\hline Severe & 4 \\
\hline
\end{tabular}

Table 2. Prevalence of degeneration of each grade of severity at each lumbar intervertebral discs level.

\begin{tabular}{|l|l|l|l|l|}
\hline Disc space & Grade 1 & Grade 2 & Grade 3 & Grade 4 \\
\hline D12-L1 & $10.8 \%$ & $2.7 \%$ & $2.7 \%$ & 0 \\
\hline L1-L2 & $6.8 \%$ & $1.4 \%$ & 0 & $1.4 \%$ \\
\hline L2-L3 & $10.8 \%$ & $1.4 \%$ & 0 & 0 \\
\hline L3-L4 & $6.8 \%$ & 0 & $2.7 \%$ & $2.7 \%$ \\
\hline L4-L5 & $5.4 \%$ & 0 & $1.4 \%$ & $1.4 \%$ \\
\hline L5-S1 & $6.8 \%$ & $4.1 \%$ & $4.1 \%$ & 0 \\
\hline
\end{tabular}

Table 3a. Incidence of degenerative changes of the lumbar spine according to the number of jumps performed by the parachuting instructors.

\begin{tabular}{|l|l|l|l|l|}
\hline $\begin{array}{l}\text { Number of } \\
\text { jumps }\end{array}$ & Grade 1 & Grade 2 & Grade 3 & Grade 4 \\
\hline$<100$ & 0 & 0 & 0 & 0 \\
\hline $101-200$ & $12.2 \%$ & 0 & $1.4 \%$ & 0 \\
\hline $201-300$ & $10.8 \%$ & $4.2 \%$ & $1.4 \%$ & 0 \\
\hline $301-400$ & $12.2 \%$ & $2.7 \%$ & $1.4 \%$ & 0 \\
\hline$>400$ & $12.2 \%$ & $2.7 \%$ & $6.7 \%$ & $5.5 \%$ \\
\hline
\end{tabular}

Table 3b. Incidence of degenerative changes of the lumbar spine according to the age of the parachuting instructors.

\begin{tabular}{|l|l|l|l|l|}
\hline Age & Grade 1 & Grade 2 & Grade 3 & Grade 4 \\
\hline $20-29$ & $20.3 \%$ & $2.7 \%$ & 0 & 0 \\
\hline $30-39$ & $21.6 \%$ & $4.1 \%$ & $1.4 \%$ & 0 \\
\hline $40-49$ & $5.5 \%$ & $2.8 \%$ & $5.4 \%$ & $5.5 \%$ \\
\hline$>49$ & 0 & 0 & $4.1 \%$ & \\
\hline
\end{tabular}

\section{Results} the lumbar spine. Thirty five $(47.4 \%)$ instructors had doubtful radiographic changes, 7 (9.6\%) had mild degeneration, 8 (10.9\%) had moderate degenerative disease radiographic more often involved in the degenerative process (Table 2), though the severe degenerative changes were found more often -S1 segment. Degenerative changes in professional parachuting and sky diving (Table 3a), more significant degenerative changes tend to increase with age (Table 3b). morll nodes were found in $6(8.1 \%)$ sition zone. Decreased lumbar lordosis was measured in one percent. Traction spurs - 
osteophytes were identified in $5(6.8 \%)$ and disc space narrowing was found in 13 $(17.6 \%)$ subjects, mainly at the L5-S1 intervertebral space. Spondylolysis of L4-L5 segment was found in 9 (12.2) subjects with documented progressive spondylolisthesis in two (Figures 1-3). Spondylolysis of L3-L4 segment was found in one, with no evidence of progression. On anteroposterior radiographs, transitional vertebrae were demonstrated in $2(3.3 \%)$ instructors and large transverse processes in one. Spina bifida occulta of S1 was seen in $9(12.2 \%)$ subjects and of L5 in $2(2.7 \%)$.

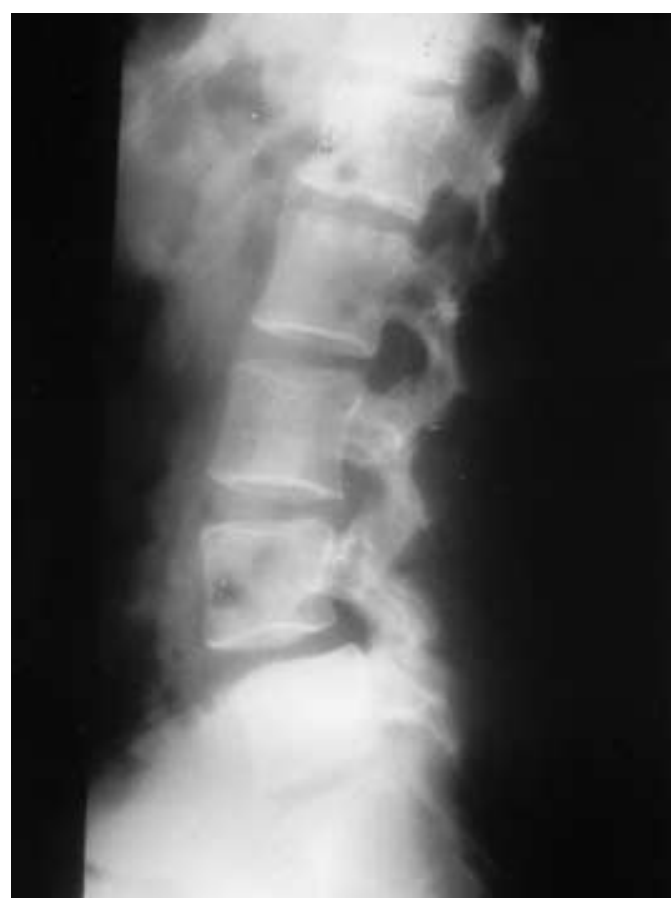

Fig 1. At commencement of the duty as parachuting instructor, alignment of the lumbar spine is normal, there are no signs of degenerative spondylolysis.

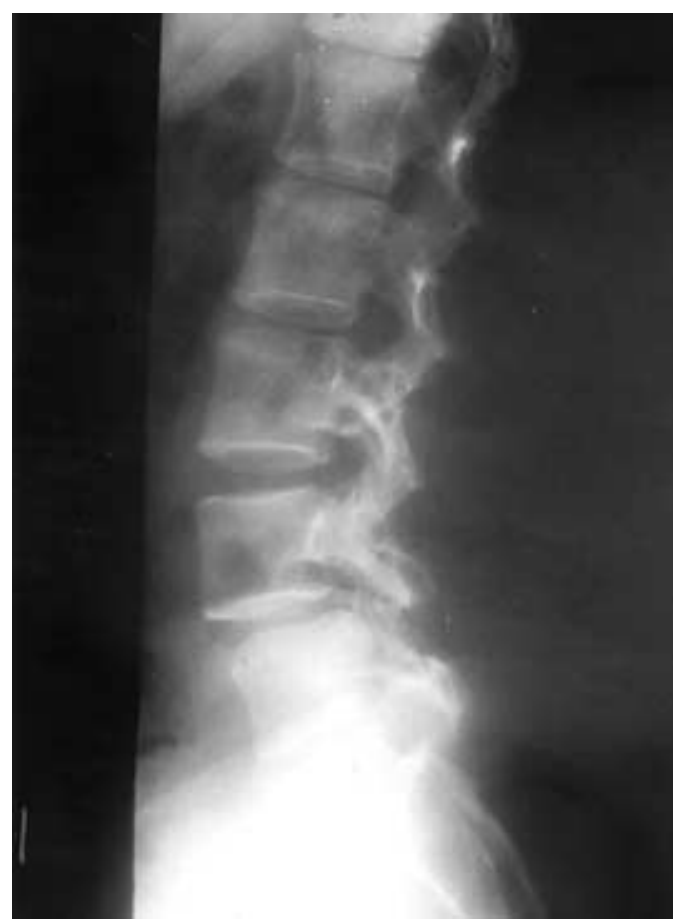

Fig 2. After 5 years there is L4-5 spondylolysis.

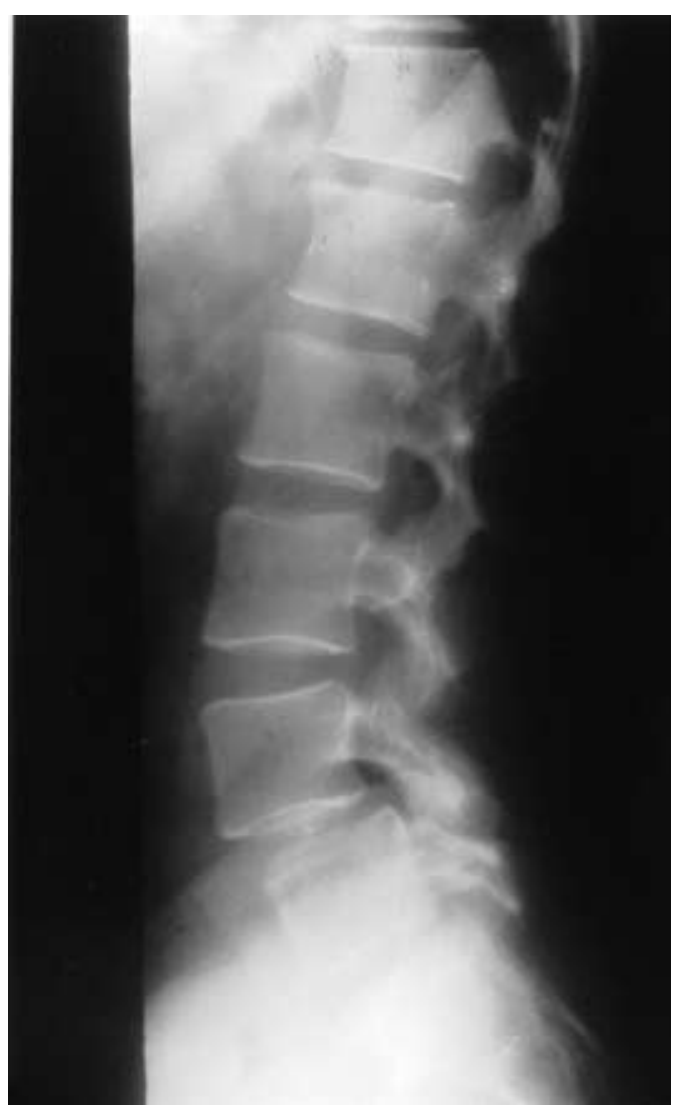

Fig 3. Eight years after commencement of duty as parachuting instructor, Grade I L4-5 spondylolisthesis is evident.

No correlation could be demonstrated between the severity of the radiographic changes and prevalence and severity of low back pain.

\section{Discussion}

Parachuting, be it static line or free fall, is not risk free. The risk of acute injury is well documented in several large population studies $(2-5,7)$. Injury is most commonly the result of badly performed landing causing 83.8 percent of all accidents (3).

Axial forces acting on the skeleton during parachuting are tremendous. During parachute opening, the spine is subjected to deceleration in the order of $4.0 \mathrm{~g}$ for a standard military parachute (10) and 3.0 to $15 \mathrm{~g}$ during the opening of a skydiving sport parachute (11). On landing, peak deceleration g-forces acting on the spine are 3.2 to $17 \mathrm{~g}$ depending on canopy type (11). Maximal spinal tolerance to acceleration or deceleration g-forces was determined to be at $20 \mathrm{~g}$ (12). This figure was calculated for acute injury. However, the cumulative impact of repeated sub maximal strains inflicted by repeated parachuting has not been hitherto determined. Worth a mention is that parachute training for static line does involve in itself a fair amount of stress.

Numerous studies confirm the progression of disc degenerative changes with increasing age. There is also an agreement as to the role of mechanical stress to the spine in the development of degenerative changes of the 
discs (13), also severe degenerative change at L5-S1 level is not uncommon in very active individuals. The vertical stress induced by parachuting is greatest in the feet and ascends gradually upwards. At the level of the lumbar spine it is estimated to be one third of the force inflicted on the feet (26). Our study shows that young parachutists had a considerable degree of degenerative changes in the lumbar spine $(73.4 \%)$ as compared to the prevalence reported in other studies in nonparachuters. In those studies in an investigated population beginning at age 35 routine X-rays of the lumbar spine were taken. The occupation of the investigated population included manual workers as well as business and professional workers. A mean of $65 \%$ of grade $2-4$ disc degeneration was found (39). Hence parachuting seems, therefore, to hasten the normal degenerative process.

The prevalence of spondylolysis among parachuting instructors was 13.6 percent as compared to only 6 percent in the general adult population (15).

The cause of spondylolysis is unclear. Genetic factors probably play some role because 26 percent of the first-degree relatives of subjects with demonstrable spondylolysis have a similar problem (27). Other evidence suggests that spondylolysis is an acquired defect, related to mechanical loading on the spine. It is more common among people who load their spines particularly vigorously, such as gymnasts (28), weightlifters (29) and fast bowlers in cricket (30). Conversely spondylolysis is never seen in the fetus or in new-born children $(27,31)$, it is rare until the age of 5 years, is absent in people who have never walked (32), and is not found in other primates who do not walk upright (33). It is reasonable to conclude from the available evidence that spondylolysis may be caused by excessive mechanical loading on a spine that may be predisposed to injury by some inherited weakness in the pars interarticularis. Experiments on isolated cadaveric vertebrae have confirmed that fracture of the pars resembling spondylolysis can be caused by simulating a hyperflexion injury (34), or by applying posteriorly directed forces to the inferior articular processes (35). Also it was found on cadaveric lumbar spine that activities involving alternating flexion and extension movements cause large stress reversals in the pars and pose the greatest threat of spondylolysis (36), hence one may conclude that parachuting, which involves excessive mechanical load, axial and bending loads $(22,25)$ may contribute significantly to the development of spondylolysis.

The implications of the presence of spondylolysis in paratroopers are quite controversial. Other studies suggest that skeletally mature high performance athletes can pursue strenuous short-term activities without risking progression of spondylolysis to listhesis (16). Those of our subjects identified as having progressive spondylolisthesis have withdrawn from parachuting. In our opinion it would be wiser to advise individuals with symptomatic spondylolysis to refrain from parachuting. Those with asymptomatic spondylolysis should be closely followed.

Spina bifida occulta was found in 14.9 percent of the parachuting instructors. In a cohort study done in the general population in Israel, prevalence rate of S1 spina bifida occulta was 33 percent in male aged 18-50 years (14). The association of spina bifida and spondylolysis was noted in the past (37), but in our study only one parachuting instructor had a coexistence of both, hence we consider the high incidence of spina bifida occulta to be incidental.

Based on the results of our study parachuting predisposes to spondylolysis and to degenerative changes of the lumbar spine. Further study needs to be done comparing parachuting instructors to a non-parachuting group or equivalent physically active individuals, in order to assess the effect of sport-background on the development of degenerative changes.

We suggest that symptomatic subjects withhold from participating in parachuting activities. Whether asymptomatic young men with degenerative spinal changes have to be withdrawn from parachuting needs further investigation and follow up.

\section{References}

1. Petras AF, Hoffman EP. Roentgenographic skeletal injury patterns in parachute jumping. Am $\mathcal{F}$ Sports Med 1983;11:325-328.

2. Amamilo SC, Samuel AW, Hesketh KT, Moynihan FJ. A prospective study of parachute injuries in civilians. F Bone foint Surg [Br] 1987;69:17-19.

3. Ellitsgaard N. Parachuting injuries: a study of 110,000 sports jumps. $\mathrm{Br} \quad \mathcal{F}$ Sports Med 1987;21:13-17.

4. Essex-Lopresti P. The hazards of parachuting. $B r \mathcal{F}$ Surg 1946;34:1-13.

5. Farrow GB. Military static line parachute injuries. Aust N Z J Surg 1992;62:209-214.

6. Kirkpatrick AW, Smallman TV. Spondylolysis and spondylolisthesis in military parachutists. Mil Med 1991;156:687-690.

7. Krauss U, Mischkowsky T. Severe parachuting accident. Analysis of 122 cases. Unfallchirurg 1993;96:299-304.

8. Mustajoki P, Nummi J, Meurman K. Permanent changes in the spines of military parachutists. Aviat Space Environ Med 1978;49:823-826.

9. Frymoyer JW, Newberg A, Pope MH, Wilder DG, Clements J, MacPherson B. Spine radiographs in patients with low-back pain. An epidemiological study in men. $f$ Bone foint Surg [Am] 1984;66:1048-1055.

10. Neel SH. Medical aspects of military parachuting. Mil Surg 1951;108:91-105.

11. Reid DH, Doerr JE, Doshier HD, Ellertson DG. Acceleration and opening shock forces during freefall parachuting: physiological studies of military parachutists via FM-FM telemetry.3. Aerospac Med 1971;42:1207-1212.

12. Laurell L, Nachemson A. Some factors influencing spinal injuries in seat ejected pilots. Aerspace Med 1963;34:726-729. 
13. Andersson GBJ. The epidemiology of spinal disorders in: Frymoyer J.W. ed. The Adult Spine, Principles and Practice. Raven Press. New York 1991.

14. Avrahami E, Frishman E, Fridman Z, Azor M. Spina bifida occulta of $S 1$ is not an innocent finding. Spine 1994;19:12-15.

15. Rosenberg NJ, Bargar WL, Friedman B. The incidence of spondylolysis and spondylolisthesis in nonambulatory patients. Spine 1981;6:35-38.

16. Comandre FA. Spondylolysis and spondylolisthesis in young athletes: 28 cases. $\mathcal{F}$ Sports Med 1988;28:104-107.

17. Semon RL, Spengler D. Significance of lumbar spondylolysis in college football players. Spine 1981;6:172-174.

18. Corrigan BC, Maitland GD: Practical Orthopaedic Medicine: Spondylolysis. Cambridge. Cambridge University Press, 1987.

19. Newman PH: Spondylolisthesis. Physiotherapy 1974; 60:14-16.

20. Klinghoffer L, Murdock MG: Spondylolysis following trauma. Clin Orthop 1981; 166: 72-74.

21. Cope R. Acute traumatic spondylolysis. Report of a case and review of the literature. Clin Orthop 1988;230:162-165.

22. Dee R. Principles of Orthopaedic Practice: Spondylolysis and Spondylolisthesis. New York, McGraw Hill, 1982.

23. Wiltse LL, Newman PH, Macnab I. Classification of spondylolysis and spondylolisthesis. Clin Orthop 1976;117:23-29.

24. Letts M, Smallman T, Afanasiev R, Gouw G. Fracture of the pars interarticularis in adolescent athletes: a clinical-biomechanical analysis. F Pediatr Orthop 1986;6:40-46.

25. Ichikawa N, Ohara Y, Morishita T, Taniguichi Y, Koshikawa A, Matsukura N. An aetiological study on spondylolysis from a biomechanical aspect. $\mathrm{Br} \mathcal{F}$ Sports Med 1982;16:135-141.
26. Aleksejev AP. Lumbosacral pain symptoms in parachutists. Voennomed $\mathcal{F}$ 1971;2:70-71.

27. Wiltse LL. The etiology of spondylolisthesis. $\mathcal{f}$ Bone foint Surg [Am] 1962;44:539-560.

28. Jackson DW, Wiltse LL, CirincoIne RJ. Spondylolysis in the female gymnast. Clin Orthop 1976;117:68-73.

29. Kotani PT, Ichikawa N, Wakabayashi W, Yoshii T, Koshimune M. Studies of spondylolysis found among weightlifters. Br F Sports Med 1971;6:4-12.

30. Hardcastle P, Annear P, Foster DH, Chakera TM, McCormick C, Khangure M, Burnett A. Spinal abnormalities in young fast bowlers. F Bone foint Surg [Br] 1992;74:421-425.

31. Newman PH. The aetiology of spondylolisthesis. $\mathcal{F}$ Bone foint Surg [Br] 1963;45:39-59.

32. Rosenberg NJ, Bargar WL, Friedman B. The incidence of spondylolysis and spondylolisthesis in nonambulatory patients. Spine 1981;6:35-38.

33. Schults A. Age changes and variability in gibbons. A morphological study on a population sample of man-like ape. Am F Phys Anthropol 1944;2:11-20.

34. Lamy C, Bazergui A, Kraus H, Farfan HF. The strength of the neural arch and the etiology of spondylolysis. Orthop Clin North Am 1975;6:215231.

35. Cyron BM, Hutton WC, Troup JD. Spondylolytic fractures. F Bone foint Surg [Br] 1976;58:462-466.

36. Green TP, Allvey JC, Adams MA. Spondylolysis Bending of the inferior articular processes of lumbar vertebrae during simulated spinal movements. Spine 1994;19:2683-2691.

37. Wiltse LL. Spondylolisthesis in children. Clin Orthop 1961;21:156-163.

38. Murray-Leslie CF, Lintott J, Wright V. The spine in sport and veteran military parachutists. Ann Rheum Dis 1977;36:332-342.

39. Lawrence JS. Disc degeneration. Its frequency and relation to symptoms. Ann Rheum Dis 1969; 28: 121-138. 